\title{
Potential Application of Yoga-Preksha-Meditation to Prevent Stress-Induced Anger in Healthy Adults - A Pilot Study
}

\author{
Shweta Sharma ${ }^{1}$, Khushbu Jain ${ }^{2}$, Ajay Kumar Sharma ${ }^{3}$, Vijay Kalia ${ }^{4}$, Viney Jain ${ }^{1}$
}

\section{Shweta Sharma ${ }^{1}$, Khushbu Jain², Ajay Kumar Sharma², Vijay Kalia ${ }^{4}$, Viney Jain ${ }^{1}$ \\ 'Department of Yoga and Science of Living, Jain Vishva Bharti Institute Ladnun, Rajasthan, INDIA. \\ ${ }^{2}$ Morarji Desai National Institute of Yoga, New Delhi, INDIA. \\ ${ }^{3}$ Adhyatm Sadhna Kendra, Chattarpur, New Delhi, INDIA. \\ ${ }^{4}$ Department of Neurophysiology, National Institute of Mental Health and Neuro Sciences (NIMHANS), Bangalore, Karnataka, INDIA.}

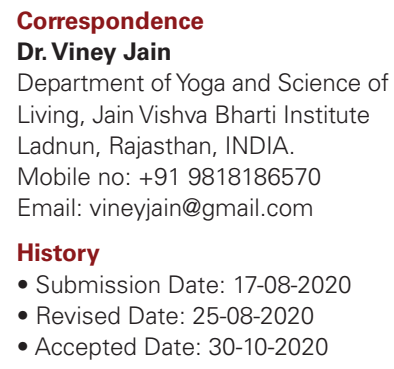

Article Available online http://www.ijmedph.org/v10/i4

\section{Copyright}

(C) 2020 Phcog.Net. This is an openaccess article distributed under the terms of the Creative Commons Attribution 4.0 International license.

\begin{abstract}
Background: Responses to perceived-stress trigger toxic emotions of anger. Uncontrolled anger outburst enhances aggressiveness, disrupts personal relationships and social harmony; impairing quality of life. Development of cost-effective preventive strategies to reduce levels of stress, anger and violence is vital for public health. Objectives: To (i) quantitatively investigate relationships between perceived-stress, anger and quality of life; (ii) identify vulnerable individuals using stress-anger reactivity and (iii) explore the effectiveness of Preksha-Meditation practice as a preventive strategy. Methods: In a single-arm pre- and postintervention study, healthy adults recruited from 7-day residential Preksha-Meditation training camps were administered Preksha-Meditation. Pre- and post-intervention levels of variables, measured by validated and reliable self-report questionnaires, from 50 subjects could be analyzed and compared using t-test. Results: Despite heterogeneous scores, perceivedstress and anger correlated positively. Quality of life correlated negatively with both stress and anger. Assessment of individual's stress-anger reactivity can identify vulnerable persons who develop uncontrollable anger. Post Preksha-Meditation, average scores of perceivedstress and anger declined significantly. Stress-anger-reactivity was reduced in majority (70\%) of subjects, indicating enhancement of coping capacities. Interestingly, males displayed larger reductions in levels of perceived-stress-anger and in stress-anger reactivity leading to better quality of life. Conclusion: Intense PM training in short-term retreats is a feasible and costeffective approach to reduce stress-induced anger. Comprehensive longitudinal studies on larger samples to verify and extend the present preliminary findings are warranted before undertaking large-scale applications to prevent increased domestic violence during stressful events, like infectious disease pandemics.
\end{abstract}

Key words: Stress-anger reactivity, Uncontrolled anger, Violent behaviour, Quality of life, Preksha-Meditation, Pandemics, Preventive strategy.

\section{INTRODUCTION}

The increasing levels of stress, anger, aggressiveness and violence in contemporary societies are serious issues for public health. High levels of perceived stress (PST) are closely associated with negative emotions including anger, anxiety and depression experienced by a large number of individuals. Increasing levels of PST and ANG constitute major risk-factors for mental and physical health disorders, ${ }^{1,2}$ cardio-vascular diseases in particular. ${ }^{3,4}$ Emotion of anger is also positively correlated with, aggressive, anti-social and violent behaviors ${ }^{5}$ that inflict high psychological and physical harm to individuals and society as a whole. Development of effective strategies, therefore, is a research priority.

Emotions and cognition are important determinants of behavior. Complex interplay between experience, expression and control of anger influences many dimensions of inter-personal and social behaviors. A precursor of aggressive behavior, anger can be defined as an unpleasant negative emotional response triggered by feelings of frustration and

events perceived as offensive, hostile or threatening. At the psycho-physiological level, anger modifies the haemo-dynamics, the autonomic nervous system (ANS) activity, functioning of neurotransmitters and perturbs cognition, decision-making processes and behavior. ${ }^{6}$ Frequent unrestrained or uncontrollable physical and verbal expressions of intense anger are detrimental to personal relationships and social harmony. Increasing incidences of domestic violence and road rage escalating sometimes even to homicides are being reported worldwide. Suppression or inward directing of anger, on the other hand, leads to depression and suicides. ${ }^{1}$ In addition to heritable pre-disposition to anger, many bio-psycho-social and environmental modifying factors may contribute to the development of angry personality traits. Experience of PST by individuals is one of the major risk-enhancing factors. Since subjective appraisal underlies the perception of stress, its intensity, responses and consequences are likely to vary from person to person. In response to the increasing external and internal energy demands

Cite this article : Sharma S, Jain K, Sharma AK, Kalia V, Jain V. Potential Application of Yoga-preksha-meditation to Prevent Stress Induced Anger in Healthy Adults - A Pilot Study. Int J Med Public Health. 2020;10(4):207-12. 
posed by stressors (such as unpleasant life threatening events, interpersonal relations or unexpected natural or man-made environmental calamities), several dynamic processes become operative at biological, psychological and behavioral levels. ${ }^{7}$ These changes are normally adaptive and transitory, since homeostasis is restored after the stressors are removed. ${ }^{8}$ Under conditions of chronic persistence of stressors, the PST-responses may become maladaptive due to presence of high levels of stress-hormones. Harmful PST-induced consequences can be prevented or reduced by coping strategies functioning at cognitive, emotional and behavioral levels. ${ }^{910}$ Individuals with high PST-reactivity and deficient coping are unable to control their anger, become vulnerable to indulge in violence and may need therapeutic help. ${ }^{11}$

Cognitive-behaviour therapy (CBT) has been used to treat anger disorders with moderate success. ${ }^{12}$ Administration of CBT requiring expert advice by clinical psychologists and psychiatrists is costly and difficult to offer on large scale. In recent years, alternative strategies based on yoga are being investigated. Yoga, rooted in Indian philosophy, is a holistic way of life directed to achieve higher consciousness. The discipline of yoga aims to integrate the physical, mental and spiritual aspects of living with consciousness. ${ }^{13}$ It is noteworthy that to achieve this aim, the comprehensive ashtanga (eight-component) yoga system described by Maharishi Patanjali includes a series of practices - yam (self-restrain), niyam (rules for right conduct) followed by practices of asanas (postures) and pranayam (proper breathing), Pratyahara (restrain on sensuous nourishment), Dharana (focused attention), Dhyana (meditation) and Samadhi (state of supreme consciousness, liberation and bliss).

Numerous empirical studies carried out in the last few decades have shown that practice of yoga modules comprising diverse combinations of yoga components, are effective in preventing and healing several psycho-somatic disorders thereby improving well-being and quality of life. ${ }^{14}$ Beneficial effects of yoga have been reported in managing stress, anger and associated mental and physical health disorders. ${ }^{15}$

Meditation practices derived from various ancient spiritual traditions are of particular interest in the present context. Common examples are: Transcendental Meditation (TM) involves focussed attention on a mantra based on Vedic philosophy; Buddhist meditation technique Vipaasana and its western version Mindful Meditation (MM) employ practices of unbiased and non-judgemental witness of thoughts, feelings and events; and Preksha Meditation (PM), a Jain yoga technique based on practices of deep perception and relaxation of the body followed by contemplation on the true nature of the Self. Effectiveness of TM and MM, specifically for management of PST induced anger has not been examined fully and requires further research. ${ }^{16}$

The present pilot study was, therefore, undertaken to explore the effects of PM on the PST induced anger; since PM is a comprehensive multicomponent system of spiritual meditation, which integrates practices of simple yogic exercises, deep perceptions of body sensations with autosuggestion and contemplation.

Based on ancient Jain practices of dharma-dhyana (meditation on the dharma i.e. nature of a substance), PM has been developed after extensive experimentation. ${ }^{17,18}$ Preksha means to perceive with full awareness and equanimity - without bias, passion, attachment or aversion. PM is a system of meditation to directly perceive and realize the most subtle aspects of one's own body, mind and consciousness; leading to realization of one's true self. Very briefly, the main components of PM are:

- Kayotsarga (Body-Transcendence): Conscious relaxation of mind-body to contemplate on the pure nature of the self detached from the body.
Antaryatra (InternalTrip): Perception of Sushumna up to Gyana Kendra.

- Swas-Preksha (Perception of Breathing): Breathing with awareness.

- Sharir-Preksha (Perception of Body): Whole-body awareness.

- Chaitanya Kendra Preksha (Perception of Psychic-Centers): Perception of Chakras (neuro-endocrine glands).

- Leshya-dhyana (Perception of Psychic-Colors): Visualization of colors associated with benign personality types.

- Anupreksha (auto-suggestion): Reciting and contemplating on suggestions concerning achievement of a desirable objective. This holistic system of PM can be modified to suit the situation, the capacities of the practitioners and the desired objective, Practice of PM is becoming increasingly popular, with training camps being regularly organized nationally and internationally at various locations. Empirical studies have demonstrated many beneficial effects of PM practices on the mental health of children and adult populations. ${ }^{19-21}$

\section{Objectives}

The present study was undertaken to (i) quantitatively study the relationships between perceived stress (PST), anger (ANG) and quality of life (QOL) in a sample of normal healthy adult population; (ii) identify individuals with high PST-ANG reactivity and (iii) investigate the effects of Preksha-Meditation (PM) practice on PST, ANG and QOL.

\section{Methods}

\section{Ethical Clearance}

The present study including the use of Hindi versions of SRQ's for measuring the psychological variables of PM camp participants was approved by the Research Review Board of Jain Vishva Bharti Institute (Deemed University), Ladnun, Rajasthan, India.

\section{Research Design}

Cross-sectional single arm pre-post study design was used for the pilot study.

\section{Study Samples and Settings}

Subjects were recruited from participants in 7 day-long residential Preksha-meditation camps conducted between 2016 and 2018 in Delhi (20 camps) and Ladnun, Rajasthan (4 camps). Number of participants in each camp varied between 15 to 20 and included normal healthy adults as well as those suffering from chronic psychosomatic ailments. For the present study, subjects suffering from ailments were excluded. Normal healthy subjects (males and females, 18 to 80 years), who had no previous experience of PM, were recruited after informed consent for participation in the study was obtained.

\section{The Socio-demographic Characteristics of the Study Population}

The sample comprised 34 males (45\%) and 41 females (55\%), from middle-class well-educated families - 12 higher secondary, 33 graduates and 30 postgraduates. Marital status: married 62; single 12; separated 1. Working status: 24 business persons; 18 in service; 24 house wives; 7 students; and 2 retired persons. Vegetarians were 69 and 6 were omnivores.

\section{Measurements of Psychological Variables}

The three psychological variables PST, ANG and QOL were measured by Hindi versions of validated self-report questionnaires (SRQ). The 
convergent validities of Hindi versions measured by correlation method were between 0.60 and 0.84 . The Hindi translations, along with the original English versions were also submitted to the Research Review Board. Reliability was measured by the test-retest method.

\section{Perceived Stress (PST) Score}

The levels of PST were assessed by a modified stress index questionnaire. ${ }^{22}$ Scale consists of 16 items including physical, emotional and relationship stressors. Each item was measured by a score of 4,3,2,1 for the following responses: mostly, usually, sometimes or rarely, respectively. Responses were summed into an overall score. Reliability was 0.70 .

\section{Anger (ANG) Score}

Anger was measured by the modified ANG-SRQ consisting of 16 items assessed on a 4-point scale. ${ }^{23}$ Reliability was 0.51 .

Quality of life (QOL) Score QOL-score was assessed by modified Hindi translated World Health Organization Quality of Life Instrument. ${ }^{24}$ This scale consists of 20 items on a 4 point scale. Measured Reliability was 0.84 .

\section{Preksha-Meditation (PM)-Module and Its Administration}

Preksha-Meditation module shown in Table 1 was strictly followed by all the participants under supervision of expert instructors. It is noteworthy that the module includes most of the components of Ashtanga Yoga. Simple vegan meals were served during the stay in the camp.

\section{Data Analysis}

The data recorded on printed prescribed forms was double entered in Microsoft Excel Sheet and validated. A clean database was generated and copied into the SPSS sheet (version 25.0). The data was analyzed using SPSS (version 25.0, IBM Corporation) and Data Analysis toolpack software of Microsoft Excel (2007). Subjects, whose responses to SRQ in the printed forms were incomplete or had errors, were eliminated from the data analysis. Average values and standard deviations for each variable were calculated from the data and analysed for statistical significance using a paired sample t-test. Effect-sizes were estimated from mean values and standard deviation values using Cohen's d. Average correlation coefficient, $r$ (Karl Pearson's correlation) between two variables was calculated from respective scatter-plots by best fit method. Data Analysis tool-pack software SPSS 25 (IBM) program and Microsoft Excel (2007) were used. The heterogeneity in PST-ANG reactivity was categorised as low (L), moderate (M) and high (H) scores of PST and ANG. The pre- and post-distributions in resultant 9 compartments were compared.

\section{RESULTS AND DISCUSSION}

Only 50 subjects complied with the request to submit the completed SRQ forms before leaving PM training camps. Table 2 compares the average pre- and post-PM scores for these 50 subjects.

Intensive PM Practice in group format in the camp significantly reduced the average scores of ST and ANG and increased the QOL scores in the study population. The calculated effect-sizes due to PM practice (Table 2) are moderate and comparable with those reported earlier for eduction of PST and improvement in QOL in traditional meditation practice retreats. ${ }^{25}$ Previous studies on elderly subjects have also reported reduced stress and improvements in QOL through PM administered in individual format for a month (30 min on alternate days) followed by home practice for 3 months. ${ }^{21}$ Improvement in mental health status by PM practice has also been reported in female business executives. ${ }^{20}$ Qualitatively, the results appear to be generally similar to those reported for TM and MM for anger management. ${ }^{26-28}$ For appropriate quantitative comparisons, studies on similar sample populations using similar methodologies should be undertaken in future research.

To investigate the effects of PM on relationships between the psychological variables, measured values of variables are plotted as functions of each other in Figure 1 and 2.

Despite large inter-individual variability, positive relationships between PST and ANG scores are noticeable (Figure 1). Observed heterogeneity indicates that the participants differ greatly in their susceptibilities for the development of anger in response to PST. Importantly, reductions in PST and ANG by practice of PM are clearly noticeable through the scatter of individual values (Figure 1). The average Pearson's correlation coefficient ' $r$ ' (estimated by best fit program) was reduced from 0.58 to 0.50 after PM practice, suggesting a weakening of the correlation between PST and ANG.

The correlations between PST and QOL and ANG and QOL scores (Figure 2) demonstrate a larger inter-individual variability. Nonetheless, negative correlations are discernable. The estimated average Pearson's correlation coefficient for PST-QOL is reduced post-PM to -0.26 from -0.49 pre-PM; similarly, that between ANG and QOL also declined from -0.42 to -0.27 , suggesting that practice of $\mathrm{PM}$ weakens the negative effects of PST and ANG on QOL.

Post-PM decreases in the average PST-ANG reactivity may be due to enhancements in the coping capacities and emotional regulation induced by the practice of the PM module. These effects are resultant of cumulative influence of the various components of PM module. The precise contributions of individual components and the underlying mechanisms remain yet to be elucidated. The practice of Kayotsarga, combining relaxation with contemplation on the true nature of the Self (differing from yoga-nidra or mindfulness relaxation) could effectively reduce attachment to the body leading to depletion of the body-ego and enhancing disposition to forgive. ${ }^{29}$ Reducing body attachment is expected to decrease PST and ANG levels and improve cognition, reappraisal and emotional regulation. Monitoring ectodermal activity (EDA) by galvanic skin responses (GSR) during the practice of Kayotsarga indicated significant reductions in the activity of sympathetic nervous system. ${ }^{29}$ -Neuro-imaging studies have shown that EDA correlates with the activities of brain regions involved in cognitive, attention and emotional

\section{Table 1: Daily Schedule of Preksha-Meditation Module.}

\begin{tabular}{|c|c|c|}
\hline S. No. & Activity & Time and Duration \\
\hline 1. & Wake up Early Morning & 4:30 AM \\
\hline 2. & Preksha-Meditation Practical & $\begin{array}{c}60 \text { min twice a day (Morning and } \\
\text { Evening) }\end{array}$ \\
\hline 3. & Asanas and Pranayam & $\begin{array}{c}60 \text { min twice a day (Morning and } \\
\text { Evening) }\end{array}$ \\
\hline 4 & Arham Mantra Chant & Once a day (Morning) \\
\hline 5 & Anupreksha (contemplation) & 30 min Once a day (Morning) \\
\hline 6 & $\begin{array}{c}\text { Kayotsarga(Transcending } \\
\text { the body) }\end{array}$ & $\begin{array}{c}40 \text { min twice a day (Morning and } \\
\text { Evening) }\end{array}$ \\
\hline 7 & Lecture on physiology & 60 min, Once a day (Afternoon) \\
\hline 8 & Swa-dhyan (Self-meditation) & Once a day (Evening) \\
\hline 9 & $\begin{array}{l}\text { Pratyahara (Restrained } \\
\text { Nourishment) }\end{array}$ & $\begin{array}{l}\text { Simple Vegan Meals } \\
\text { (breakfast, luncheon, dinner) }\end{array}$ \\
\hline 10 & $\begin{array}{c}\text { BhajanSandhya (Devotional } \\
\text { Songs) }\end{array}$ & Evening (Post-Dinner) \\
\hline
\end{tabular}


responses. ${ }^{30}$ Enhancement of parasympathetic nervous activity by Kayotsarga has also been indicated. ${ }^{31}$ These observations thus suggest that Kayotsarga influences the emotional as well as cognitive processes to effectively reduce negative emotional responses to PST.

\section{Heterogeneity in Responses to Practice of PM}

Because of large inter-individual variability of PST-ANG relationships demonstrated by the scatter-plots (Figure 1), the value of average correlation coefficient provides only a very approximate estimate about the strength of the relationship. To further analyse the heterogeneity in PST-ANG reactivity, levels of PST and ANG were classified into (1) low (L), (2) moderate (M) and (3) high (H) categories. The observed PSTANG relationships (Figure 1) could analysed in 9 compartments / subcategories shown in Figure 1 and summarized in Table 3.

Table 3 shows that the subjects in the Low PST-Low ANG (LPSTLANG) category increased by 10 (20\%) after PM-intervention. This was accompanied by decreases of 6 cases in MPST-LANG, 2 in MPSTMANG, 2 in MPST-HANG and 2 in HPST-MANG categories. Increase of 2 cases in the LPST-MANG category could be due to transitions from MPST-HANG category. Such a category-wise redistribution clearly demonstrates the effectiveness of PM in reducing PST and ANG levels as well as PST-ANG reactivity in majority of subjects. Notably, however, not all subjects responded to PM as expected. Closer scrutiny of raw data revealed that $30 \%$ subjects did not respond to PM with decline in PST/ ANG scores.

Reasons underlying such deficient-responses could be manifold: for example, inadequate compliance in the practice of PM-module in the camp setting or insufficient time for PM practice (dose-effect). Additionally, adapting to the strict discipline and simple vegan diet

Table 2: Descriptive Statistics of Pre and post PM scores of Psychological Variables

\begin{tabular}{|c|c|c|c|c|c|}
\hline \multirow{3}{*}{ Variables } & \multicolumn{4}{|c|}{ Mean } & \multirow{3}{*}{ P-Value } \\
\hline & $\mathrm{N}$ & \multicolumn{2}{|c|}{ (Standard Deviation) } & \multirow[t]{2}{*}{ Effect size } & \\
\hline & & Pre-PM & Post-PM & & \\
\hline $\begin{array}{l}\text { Perceived } \\
\text { Stress }\end{array}$ & 50 & $\begin{array}{l}33.00 \\
(8.59)\end{array}$ & $\begin{array}{l}29.00 \\
(7.29)\end{array}$ & -0.50 & $<0.001^{* *}$ \\
\hline Anger & 50 & $\begin{array}{l}28.18 \\
(9.67)\end{array}$ & $\begin{array}{l}23.62 \\
(7.28)\end{array}$ & -0.53 & $<0.001^{* *}$ \\
\hline $\begin{array}{l}\text { Quality of } \\
\text { Life }\end{array}$ & 39 & $\begin{array}{c}54.38 \\
(13.81)\end{array}$ & $\begin{array}{c}61.51 \\
(11.43)\end{array}$ & 0.56 & $<0.001^{* *}$ \\
\hline
\end{tabular}

Table 3: Effects of PM on PST-ANG Relationships: Category-wise Redistributions

\begin{tabular}{cccccc}
\multicolumn{2}{l}{ Variables } & \multicolumn{2}{c}{ Pre-PM } & \multicolumn{2}{c}{ Post-PM } \\
S.NO. & Categories & N & Percentage & N & Percentage \\
1 & LPST-LANG & 23 & $46 \%$ & 33 & $66 \%$ \\
2 & MPST-LANG & 16 & $32 \%$ & 10 & $20 \%$ \\
3 & HPST-LANG & 0 & $0 \%$ & 0 & $0 \%$ \\
4 & LPST-MANG & 0 & $0 \%$ & 2 & $4 \%$ \\
5 & MPST-MANG & 6 & $12 \%$ & 4 & $8 \%$ \\
6 & HPST-MANG & 2 & $4 \%$ & 0 & $0 \%$ \\
7 & LPST-HANG & 0 & $0 \%$ & 0 & $0 \%$ \\
8 & MPST-HANG & 3 & $6 \%$ & 1 & $2 \%$ \\
9 & HPST-HANG & 0 & $0 \%$ & 0 & $0 \%$ \\
\hline
\end{tabular}

during the camp was difficult for some participants and could contribute to increase in PST.

Inter-individual variability in the levels of PST and its responses may arise due to interplay of multiple biological, psychological and sociocultural environmental factors. In this context, it is important to note that compliance, coping styles and responses to yoga and meditation practices have been reported to be influenced by personality types. ${ }^{32}$ Since the relationships between personality and meditation are dynamic, longitudinal studies to investigate interactions between personality and PM should be planned in future for better understanding.

Other important factors responsible for heterogeneity involve the genetic pre-dispositions of individuals interacting dynamically with their developmental, physiological and psycho-social experiences. For example, it has been shown that polymorphic expressions of genes involved in the metabolism of neurotransmitters - such as serotonin and dopamine -influence anger susceptibility. ${ }^{33}$ Unpleasant experiences in early childhood could further sensitize individuals to higher stressrelated reactivity. Variations in the arousal of ANS activity and HPAaxis mediated secretion of stress hormones in response to PST have been observed. Precise elucidation of the complex psycho-biological processes underlying the emotional and behavioral responses to stress, however, remain elusive. ${ }^{34}$

Analysis of the data according to gender and age distribution of the study population revealed that the basal levels of the psychological variables as well as the effects of PM-practice are age and gender dependent.
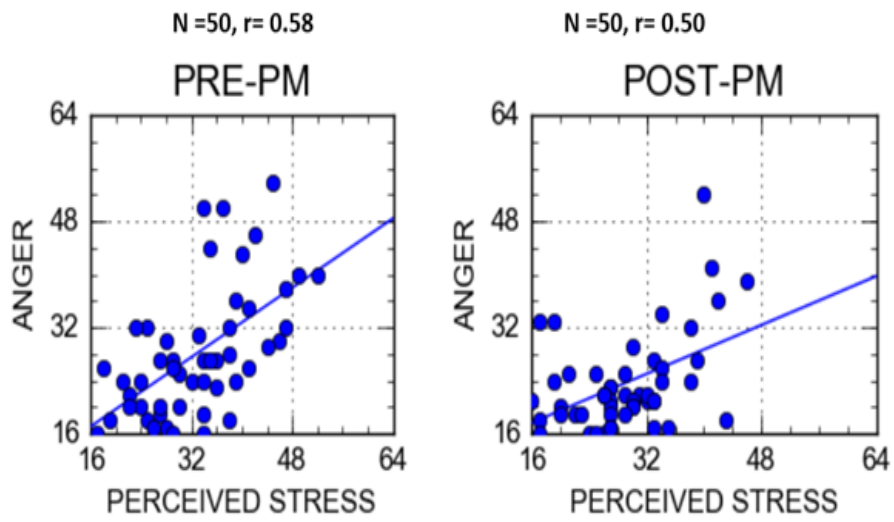

Figure 1: Comparison of Pre- and Post-Intervention PST- ANG Relationships. $(\mathrm{N}=$ Number of subjects)
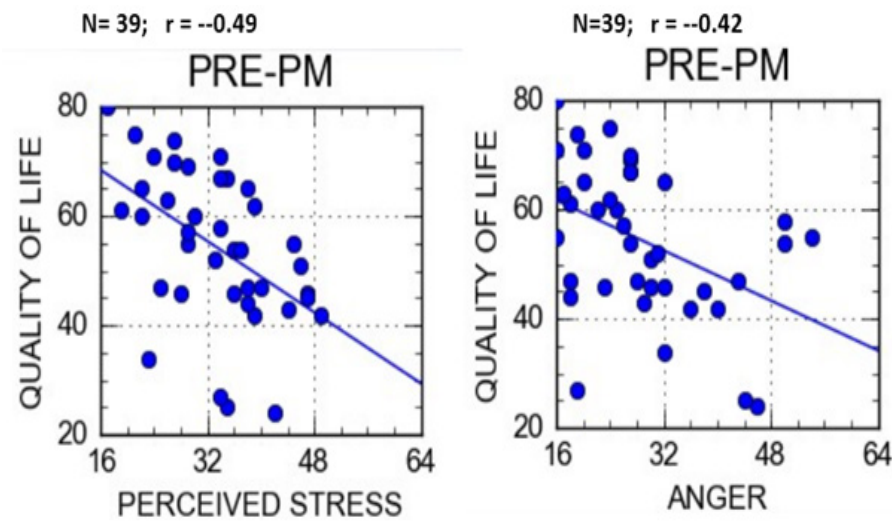

Figure 2: Correlations between PST and QOL and ANG and QOL scores. ( $\mathrm{N}=$ Number of subjects) 
Table 4 shows that the younger age group (mean age 38.38 years) experience, on the average, higher levels of PST and ANG and lower levels of QOL as compared to elderly persons (mean age 59.36 yrs.). Interestingly, after PM practice in the camp, the levels of PST and ANG were significantly reduced with effect sizes higher for the younger group. Table 5 demonstrates that females have lower mean levels of ANG, though they have higher levels of PST. These results are consistent with published

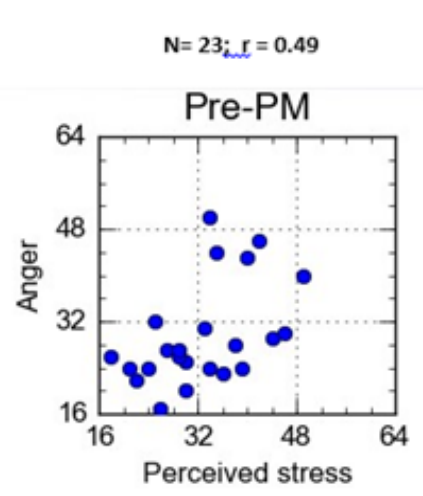

MALE

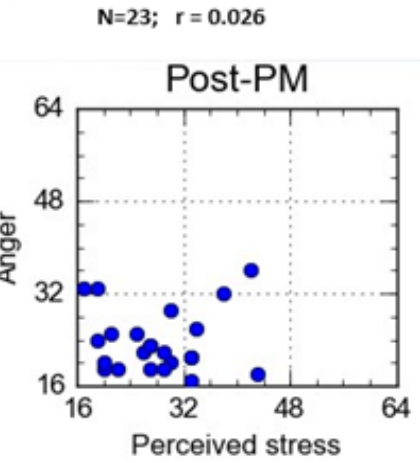

FEMALE

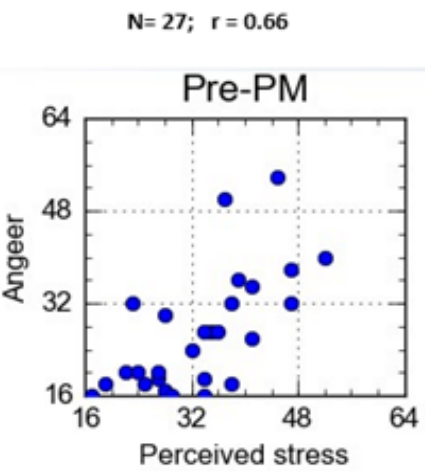

$\mathrm{N}=27 ; \mathrm{r}=0.48$

Figure 3: Comparison of PST-ANG Relationships between Male and Female Subjects. ( $\mathrm{N}=$ Number of subjects) reports. ${ }^{35}$ Interestingly, the average effectiveness of PM in reducing ANG is greater in men as compared women (Table 5). The gender differences on the modifications of the PST-ANG relationships were, therefore, scrutinized further by comparing scatter-plots (Figure 3). Interindividual variability notwithstanding, comparison of data in Figure 3a and $3 \mathrm{~b}$, supports the greater effectiveness of PM in males as compared to females. Lower effects of yoga practices in women as compared to men have also been recently reported in a study of prisoners. ${ }^{36}$ Further research on larger study samples to verify these observations and to compare with other meditation practices is warranted.

The gender differences in the relationship between PST and ANG can be understood on the basis of differences in chromosomes (XX vs XY) and the associated alterations in the brain structures, neurotransmitters and the hormonal profiles of men and women. ${ }^{37,38}$ Gender-specific changes in the functioning of the HPA axis ${ }^{39}$ and serotonin system ${ }^{40}$ are of particular interest in the present context of PM induced modifications of stress, anger and violence.

\section{Implications of the Observations for Public Health}

Increasing incidences of anger, aggression, domestic violence, anxiety, depression and suicides have been reported during extremely stressful events such as infectious disease pandemics. ${ }^{41,42}$ Popularization of Preksha Meditation, including development of online training for its practice, can provide immense public health benefits by reducing PST, anger and its negative consequences.

\section{Strengths and Limitations}

Assessment of PST-ANG reactivity to identify vulnerable individuals prone to uncontrolled anger outbursts and development of a highly cost-effective strategy with potential for large-scale applications of PM to prevent violence caused by PST induced uncontrolled anger are important strengths of the present pilot study. Major limitations are: single-arm pre-post-test study-design without a control arm; small atypical study sample; measurements of psychological variables based on self-assessment only and lack of follow-up. The findings of the study cannot be generalized because of these limitations.

Table 4: Age Dependent Effects of PM on PST, ANG and QOL

\begin{tabular}{|c|c|c|c|c|c|c|c|c|c|c|c|c|c|}
\hline \multirow{2}{*}{$\begin{array}{l}\text { Age- } \\
\text { Range }\end{array}$} & \multirow[t]{2}{*}{$\mathrm{N}$} & \multicolumn{4}{|c|}{ Perceived Stress (PST) } & \multicolumn{4}{|c|}{ Anger (ANG) } & \multicolumn{4}{|c|}{ Quality Of Life (QOI) } \\
\hline & & Pre-PM & Post-PM & $\begin{array}{c}\text { Effect } \\
\text { Size }\end{array}$ & P-Value & Pre-PM & Post-PM & $\begin{array}{l}\text { Effect } \\
\text { Size }\end{array}$ & P-Value & Pre-PM & Post-PM & $\begin{array}{c}\text { Effect } \\
\text { Size }\end{array}$ & P-Value \\
\hline $18-50$ & 31 & $\begin{array}{l}34.55 \\
(7.60)\end{array}$ & $\begin{array}{l}28.68 \\
(7.11)\end{array}$ & -0.79 & $<0.001^{\star *}$ & $\begin{array}{l}30.52 \\
(9.79)\end{array}$ & $\begin{array}{l}23.35 \\
(5.75)\end{array}$ & -0.89 & $<0.001^{\star *}$ & $\begin{array}{c}50.83 \\
(13.81)\end{array}$ & $\begin{array}{c}59.95 \\
(11.92)^{* *}\end{array}$ & 0.70 & $<0.001^{* *}$ \\
\hline $51-80$ & 19 & $\begin{array}{l}30.47 \\
(9.69)\end{array}$ & $\begin{array}{l}29.53 \\
(7.74)\end{array}$ & -0.10 & $>0.001$ & $\begin{array}{l}24.37 \\
(8.04)\end{array}$ & $\begin{array}{l}24.05 \\
(9.41)\end{array}$ & -0.03 & $>0.001$ & $\begin{array}{c}60.07 \\
(13.23)\end{array}$ & $\begin{array}{c}64.00 \\
(10.50)^{*}\end{array}$ & 0.32 & $>0.001$ \\
\hline
\end{tabular}

$(\mathrm{N}=$ Number of subjects $)$

Table 5: Gender Dependent Effects of PM on PST, ANG and QOL

\begin{tabular}{|c|c|c|c|c|c|c|c|c|c|c|c|c|c|}
\hline \multirow[t]{2}{*}{ Gender } & \multirow[t]{2}{*}{$\mathrm{N}$} & \multicolumn{4}{|c|}{ Perceived Stress (PST) } & \multicolumn{4}{|c|}{ Anger (ANG) } & \multicolumn{4}{|c|}{ Quality Of Life (QOI) } \\
\hline & & $\begin{array}{l}\text { Pre- } \\
\text { PM }\end{array}$ & $\begin{array}{l}\text { Post- } \\
\text { PM }\end{array}$ & $\begin{array}{l}\text { Effect } \\
\text { Size }\end{array}$ & P Value & Pre-PM & Post-PM & $\begin{array}{l}\text { Effect } \\
\text { Size }\end{array}$ & P-Value & Pre-PM & $\begin{array}{l}\text { Post- } \\
\text { PM }\end{array}$ & $\begin{array}{c}\text { Effect } \\
\text { Size }\end{array}$ & P-Value \\
\hline Female & 27 & $\begin{array}{l}33.30 \\
(8.98\end{array}$ & $\begin{array}{l}29.85 \\
(7.36)\end{array}$ & -0.42 & $<0.01^{\star}$ & $\begin{array}{c}26.93 \\
(10.31)\end{array}$ & $\begin{array}{c}23.52 \\
(8.61)\end{array}$ & -0.35 & $<0.01^{*}$ & $\begin{array}{c}55.71 \\
(13.88)\end{array}$ & $\begin{array}{l}60.91 \\
(8.69)\end{array}$ & 0.44 & $<0.001^{\star}$ \\
\hline
\end{tabular}




\section{CONCLUSION AND IMPLICATIONS}

Taken together, present results indicate that intense training and practice of PM in short-term retreats can effectively reduce levels of perceived stress and anger. Importantly, PM practice also reduces the strength of association between perceived stress and anger suggesting enhancement of coping strategies, resulting in prevention of violence and improvement in quality of life. Comprehensive basic and longitudinal clinical studies on diverse and large samples are warranted to verify the results of this pilot study.

\section{ACKNOWLEDGEMENT}

Financial support was provided by Asha Foundation for Wellness (AFW), Gurugram. Grateful thanks are due to participants, instructors and organizers of the residential camps for their co-operation.

\section{CONFLICT OF INTEREST}

The authors declare no Conflict of interest.

\section{Funding}

It is declared that authors have no financial involvement with the organizations of Preksha Meditation Camps.

\section{ABBREVIATIONS}

AFW: Asha Foundation for Wellness; ANG: Anger; CBT: CognitiveBehavior-Therapy; GSR: Galvanic Skin Response; H: High; JVBI: Jain Vishva Bharati Institute; L: Low; M: Moderate; MM: Mindful Meditation; N: Number of subjects; P- Value: Statistical significance; PM: PrekshaMeditation; PST: Perceived stress; QOL: Quality of Life; r: Karl Pearson correlation; SRQ: Self Report Questionnaire; TM: Transcendental Meditation.

\section{REFERENCES}

1. Utreja D, Rizvi SH. Exploring the Relationship between State, Trait Anger and Anxiety in Anxiety Disorders. International Journal of Indian Psychology. 2019;7(1):134-59.

2. Staicu ML, Cuţov M. Anger and health risk behaviors. Journal of Medicine and Life. 2010;3(4):372-5.

3. Pimple P Shah A, Rooks C Bremner JD, Nye J, Ibeanu I, et al. Association between anger and mental stress-induced myocardial ischemia. American Heart Journal. 2015;169(1):115-21.

4. Sprague J, Verona E, Kalkhoff W, Kilmer A. Moderators and Mediators of the Stress-Aggression Relationship: Executive Function and State Anger. Emotion. 2011;11(1):61-73.

5. Averill JR. Studies on anger and aggression: Implications for theories of emotion. American Psychologist. 1983;38(11):1145-60

6. Garfinkel SN, Zorab E, Navaratnam N, Engels M, Mallorquí-Bagué N, Minat $L$, et al. Anger in brain and body: The neural and physiological perturbation of decision-making by emotion. Social Cognitive and Affective Neuroscience. 2016;11(1):150-8.

7. Bhargava D, Trivedi $H$. A study of causes of stress and stress management among youth. IRA-International Journal of Management and Social Sciences. 2018;11(03):108-17.

8. Yaribeygi $H$, Panahi $Y$, Sahraei $H$, Johnston TP, Sahebkar A. The impact of stress on body function: A review. EXCLI Journal. 2017;16:1057.

9. Billings $A G$, Moos $\mathrm{RH}$. The role of coping responses and social resources in attenuating the stress of life events. Journal of Behavioral Medicine. 1981;4(2):139-57.

10. Lazarus RS, Folkman S. Stress, appraisal and coping. Springer publishing company. 1984

11. DeRivera JLG, DeLas CC, Monterrey AL, Rodriguez-Pulido F, Gracia R. Stress reactivity in the general population. European Journal of Psychiatry. 1993;7(1):511.

12. Beck R, Fernandez E. Cognitive-behavioral therapy in the treatment of anger: A meta-analysis. Cognitive Therapy and Research. 1998;22(1):63-74
13. Bhavanani AB. Role of yoga in health and disease. Journal of Symptoms and Signs. 2014;3(5):399-406.

14. Woodyard C. Exploring the therapeutic effects of yoga and its ability to increase quality of life. International Journal of Yoga. 2011;4(2):49.

15. Sumana NS, Alaka MTL, Deshpande S. Effect of integrated yoga module for anger management on heart rate variability in high school children-a pilot study. J Cardiol Curr Res. 2018;11(6):257-63.

16. Yadav PK, Yadav RAML, Sapkota NK. Anger: Its Impact on Human Body. Innovare Journal of Health Sciences. 2017;4(5):3-5.

17. Acharya T. Transmutation of Personality through Preksha Meditation. 1993;282.

18. Mahaprajna A. PrekshaDhyan: Theory and Practice ( $3^{\text {rd }}$ ed.). Ladnun, Jain Vishva Bharati. 1994

19. Jain D, Jain V, Pahuja YP, Joshi V, Parekh N, Jain V. A Pilot Study on the Effects of Yoga Practices on Aggressive Behavior and Academic Performance of Schoo Children. Poject Report submitted to Department of Education, South Delhi Municipal Corporation, New Delhi. 2014.

20. Gaur BP, Gusain VS. Impact of preksha meditation on mental health of female executives of metro city. International Journal of Yoga and Allied Science. 2017;6(1):5-12.

21. Sanchetee $P$, Jain $A$, Agarwal $H$. Preksha Meditation and Mental Health in Elderly. Journal of the Indian Academy of Geriatrics. 2017:13(3):131-8.

22. Holeyannavar PG, Itagi SK. Stress and emotional competence of primary school teachers. Journal of Psychology. 2012;3(1):29-38.

23. Reynolds NS, Walkey FH, Green DE. The anger self-report: A psychometrically sound (30 item) version. Report: A Psychometrically Sound (30 Item) Version. 1994;23:64-70.

24. WHO QOL. WHO Quality of Life Scale (WHOQOL). Psuchological Medicine 1998;28(3):551-8.

25. Khoury B, Knäuper B, Schlosser M, Carrière K, Chiesa A. Effectiveness of traditional meditation retreats: A systematic review and meta-analysis. Journal of Psychosomatic Research. 2017;92:16-25.

26. Momeni J, Omidi A, Raygan F, Akbari H. The effects of mindfulness-based stress reduction on cardiac patients' blood pressure, perceived stress and anger: A single-blind randomized controlled trial. Journal of the American Society of Hypertension. 2016;10(10):763-71.

27. Kabat-Zinn J. Mindfulness-based interventions in context: Past, present and future. Clinical Psychology: Science and Practice. 2003;10(2):144-56.

28. Shonin E, Gordon WV, Griffiths MD. Ontological addiction: Classification, etiology and treatment. Mindfulness. 2016;7(3):660-71.

29. Sharma S. Yoga- Preksha - Dhyan : The Pathway To Reduce Aggressiveness and Promote Forgiveness For Improving Quality Of Life: An Empirical Study. National seminar on Psychology of National Integration (ed.), Shyama Prasad Mukherjee College (Delhi-University), Delhi. 2019

30. Critchley HD, Melmed RN, Featherstone E, Mathias CJ, Dolan RJ. Brain activity during biofeedback relaxation: A functional neuroimaging investigation. Brain 2001;124(5):1003-12.

31. Khangarot YS, Shekhawat PS, Mishra JPN. Influence of Kayotsarga (Relaxation with self-awareness) practice on Cardio-Pulmonary Functions. Int J Yoga and Allied Sciences. 2015:4:5-10.

32. Menon P, Doddoli S, Singh S, Bhogal RS. Personality correlates of mindfulness: A study in an Indian setting. Yoga Mimamsa. 2014;46(1):29.

33. Craig IW, Halton KE. Genetics of human aggressive behaviour. Human Genetics. 2009;126(1):101-13.

34. Linden WL, Earle TL, Gerin W, Christenfeld N. Physiological stress reactivity and recovery: Conceptual siblings separated at birth?. Journal of Psychosomatic Research. 1997;42(2):117-35.

35. Calvarese M. The effect of gender on stress factors: An exploratory study among university students. Social Sciences. 2015;4(4):1177-84.

36. Jain K, Basavaraddi IV, Badoni S, Kaushik J, Gonde PPR. Effect of Yogic practices on cardiovascular system and salivary alpha amylase on Indian jail inmates. Preprint. 2020.

37. Lindberg AL, Ekström EC, Nermell B, Rahman M, Lönnerdal B, Persson LA, et al. Gender and age differences in the metabolism of inorganic arsenic in a highly exposed population in Bangladesh. Environmental Research. 2008;106(1):11020 .

38. Zaidi ZF. Gender Differences in Human Brain: A Review. The Open Anatomy Journal. 2010;2(1):37-55.

39. Goel N, Workman JL, Lee TT, Innala L, Viau V. Sex differences in the HPA axis. Comprehensive Physiology. 2011;4(3):1121-55.

40. Munro CA, Workman $\mathrm{Cl}$, Kramer $\mathrm{E}$, Hermann C, Ma $\mathrm{Y}$, Dhawan $\mathrm{V}$, et al. Serotonin modulation of cerebral glucose metabolism: Sex and age effects. Synapse. 2012;6(11):955-64.

41. Roesch E, Amin A, Gupta J, García-Moreno C. Violence against women during covid-19 pandemic restrictions. The BMJ. 2020;369(5):2-3

42. Dsouza DD, Quadros S, Hyderabadwala ZJ, Mamun MA. Aggregated COVID-19 suicide incidences in India: Fear of COVID-19 infection is the prominent causative factor. Psychiatry Research. 2020;e113145 